\title{
Intraspecific agonistic interactions in freely swimming mormyrid fish, Marcusenius macrolepidotus (South African form)
}

\begin{abstract}
South African bulldogs (Marcusenius macrolepidotus, Mormyridae) generate brief (less than $1 \mathrm{~ms}$ ) electric organ discharges (EODs), separated by much longer and highly variable inter-discharge intervals (IDIs). The diurnal and nocturnal overt behaviour and electrical activity were studied under various conditions: in isolated fish, in pairs of fish, and in a group of four fish that were kept in a "natural" large aquarium. EODs from up to four individuals were recorded simultaneously and identified. While resting during the day, isolated fish showed a broad inter-individual variability of IDI patterns, with distribution histogram modes ranging from $85.7 \mathrm{~ms}$ to $325.8 \mathrm{~ms}$. When foraging during the day, IDI modes were shorter and less variable (36.3-48.3 ms). Behaviour patterns displayed during nocturnal agonistic encounters were retreating, parallel swimming, anti-parallel display, attack, and fleeing/chasing. High-discharge-rate (HD) displays were observed at several stages of these encounters, for example, during antiparallel display (a period of low overt motor activity), or following attacks. IDI durations as short as $11 \mathrm{~ms}$ occurred during HD displays, which followed low-rate inter-HD activity almost without transition. IDI distribution histogram modes when fish showed anti-parallel display were $15.4 \mathrm{~ms}$ and $24.8 \mathrm{~ms}$, and $30.0 \mathrm{~ms}$ during nocturnal nonagonistic interactions. No overt fighting was observed once a dominance relationship was established. In a large aquarium, an approaching dominant male evoked a simultaneous discharge arrest in a group of three subdominant males.
\end{abstract}

Key words Aggression - Agonistic - Electrocommunication - Marcusenius - Mormyridae

M. Werneyer $\cdot$ B. Kramer $(\bowtie)$

Zoologisches Institut der Universität Regensburg, 93040 Regensburg, Germany

Tel. +49-941-9432263; Fax +49-941-9432905

e-mail: Bernd.Kramer@biologie.uni-regensburg.de

\section{Introduction}

The bulldog, Marcusenius macrolepidotus (Peters, 1852), is a member of the family Mormyridae, the largest family of freshwater fish endemic to Africa (approximately 200 species). It is widespread in southern Africa, including the Cunene, Okavango, and Zambezi Rivers. In east coastal rivers and lakes it ranges from Tanzania to the Umhlatuzi in Natal as its southern limit. The bulldog has also been recorded from the Upper Zaire (Skelton 1993). The specimens of the present study originate from the Crocodile River (Incomati River system, South Africa, draining into Delagoa Bay, Indian Ocean), close to the southern limit of its range where Petrocephalus catostoma is the only other mormyrid present.

All mormyrids that have been studied up to now generate brief electric organ discharges (EODs), separated by much longer inter-discharge intervals (IDIs). Though some plasticity was found in the long-term, the individual EOD waveform in general is highly stereotyped (e.g., Kramer and Westby 1985) and species specific for a community (Kramer 1996). In contrast to this, the IDI pattern is highly variable and capable of encoding different messages during social interaction (reviews by Kramer 1990; Moller 1995). Certain IDI patterns occur strictly correlated with specific motor behaviour patterns (e.g., Bauer 1972; Bell et al. 1974; Kramer 1974; Kramer 1976; Kramer and Bauer 1976). By playback of specific IDI patterns using an electric dipole, various complex motor activities in Gnathonemus petersii were evoked and the signal value of certain IDI patterns established (Kramer 1979). Despite all the progress in the technology of data acquisition and processing that has been made in recent years, electrocommunication remains difficult to demonstrate and has been studied in only very few mormyrid species.

A technical problem that is still difficult to overcome is the separation of EODs from different conspecific individuals, due to their species-typical similarity. In some previous studies of electrocommunication permitting social interactions among conspecifics, one fish was tethered to a wire 
fastened around its caudal peduncle, which made possible signal separation by amplitude (Bell et al. 1974; Bratton and Kramer 1989). Yet even with an improved technique (Graff 1987) freedom of movement of the tethered fish was greatly restricted. Another approach was to use two species with different EOD pulse durations that could be separated electronically (Kramer 1974), or to move caged individuals slowly within communication distance (Moller et al. 1989). Very few studies describe electrocommunication in unrestricted, freely moving mormyrids of the same species (Bratton and Kramer 1989; Scheffel and Kramer 1997, 2000). We used the history of polarity and amplitude of EODs, simultaneously recorded by four pairs of electrodes, in combination with the video-taped positions of the fish to assign discharges to specific individuals.

The present study shows IDI patterns that are correlated with agonistic behaviour in freely swimming $M$. macrolepidotus at night, together with their overt behaviour that was video-taped using infrared light. To our knowledge a detailed documentation of discharge activities at the various stages of an agonistic encounter between freely swimming conspecific mormyrids has not been presented previously. IDI patterns recorded from resting and foraging isolated fish are added.

\section{Materials and methods}

Eleven M. macrolepidotus from the Crocodile River (Stentor Estates near the town of Kaapmuiden, Mpuma-

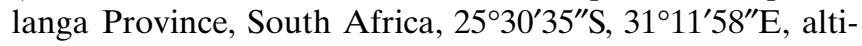
tude $432 \mathrm{~m}, 14$ February 1997, water conductivity $230 \mu \mathrm{S} /$ $\mathrm{cm}$, water temperature $25^{\circ} \mathrm{C}$ ) were used in this study. Immediately after capture they were exported to Germany. From June 1999 the fish were kept individually in 120- to 600-1 aquaria. EODs were recorded in July. From August to December 1999 all individuals were photographed (Olympus Camedia), and the standard length (SL) determined from the photographs. All fish were well beyond the $40 \%$ maturity criterion of the maximum SL that had been confirmed for this species by Kramer (1997b). Eight fish had a clear kink in the anal fin base and were therefore males; the remaining three fish without a kink were females (Skelton 1993; Kramer 1997b).

Initially a water temperature of $25^{\circ} \mathrm{C}$ was used; it was reduced for most of the experiments to $20^{\circ} \mathrm{C}$, except when imitating the hot season. Conductivity was $100 \pm 10 \mu \mathrm{S} / \mathrm{cm}$ throughout. Temperature and conductivity were measured with an electronic meter (LF91, WTW Weilheim). Between one-third and two-thirds of the water was exchanged weekly with fresh water of $90-100 \mu \mathrm{S} / \mathrm{cm}$. Thus strong changes in water conductivity were avoided, and conductivity-evoked changes in EOD waveform (Kramer and Kuhn 1993) did not occur. In August 1999 four males (fish A, E, F, and L) were transferred into an aquarium of $3 \mathrm{~m}^{2}$ bottom area that offered an environment resembling the natural one with gravel, sunken wood, stones, and plants. In the large aquarium water was exchanged less frequently, and conductivity was $89-115 \mu \mathrm{S} / \mathrm{cm}$. The other fish were still kept individually except for confrontation experiments. All animals were exposed to a 12:12 h L:D cycle and fed two times a day (not on weekends) with frozen or live Chironomus larvae, sometimes also with small earthworms.

The EODs of each fish were recorded during the day while the fish was resting. One carbon electrode each was placed in front of the head and behind the tail of a fish. A differential amplifier (GVI, Elektronische Werkstätten der Universität Regensburg, gain $10 \mathrm{x}, 1 \mathrm{~Hz}$ to $100 \mathrm{kHz}$ ) was connected to an oscilloscope (Tektronix TDS 420) that digitized the EODs with a vertical resolution of 12 bits, sampling rate $250 \mathrm{kHz}, 1,000$ points per trace. The traces were transferred to a computer and normalized to a positive peak of $1 \mathrm{~V}$ (using the signal analysis package Famos 3.1, IMC, Germany).

For confrontation experiments two fish were transferred into a tank $(240 \times 50 \times 60 \mathrm{~cm}$ high $)$ that was divided into two equal compartments by a solid, non-transparent plastic partition. A small area of the partition had small holes for water exchange, covered by a solid sheet of plastic at $8 \mathrm{~mm}$ distance, to prevent the fish from seeing each other. Observations by video camera and infrared illumination began 3 days after transfer (except for fish C and G: 94 days after transfer), starting when the room lights were switched off. When the plastic partition was removed, a fine plastic mesh was sometimes left in place to prevent the fish from damaging each other. The overt behaviour was video-taped. EODs were picked up simultaneously by four pairs of carbon electrodes (fixed to the aquarium walls), separately amplified (GV3, GVJ, Elektronische Werkstätten der Universität Regensburg), and separately recorded on four channels of an eight-channel instrumentation tape recorder (Racal StorePlus, Racal Recorders). A time-reference signal was stored on both video and instrumentation tapes to facilitate off-line synchronization. An electronic "pulse marker", triggered by EODs as well as by the timereference signal, generated a synchronization signal on the video image for precise synchronization of the EOD recordings with the sequence of video images.

Selected sections from the videotape were digitized (video card for PC, AV Master, Fast Multimedia AG) and stored on hard disk. EOD recordings were digitized at a sampling rate of $50 \mathrm{kHz}$, using an eight-channel, computerized A/D system (Hydra, Kinzinger Systeme GmbH) linked to a PC. For each selected period the outputs from all recording channels of the instrumentation tape recorder were digitized simultaneously in a single run to avoid desynchronization by slight differences in tape speed (as explained by Kramer 1974). EOD sequences were displayed on a PC screen by scrolling through the recordings using software for processing and presentation (Diadem 6, GfS Aachen). Maximum error for IDI estimation was $\pm 1 \mathrm{~ms}$. EODs from different individuals were discriminated from each other using the history of polarity and amplitude, as separately displayed for each of the four pairs of electrodes, and considering the position of the fish as shown on the video images (see Fig. 1d). Even though no top view was used, in many cases the EODs could be clearly assigned to 
individual fish. The analysis yielded sequences of IDIs for each fish accompanied by the concurrent overt behaviour. In the present study overt behaviour is illustrated by drawings, made from selected video images.

Isolated resting and foraging fish were observed during the day. Usually the experimenter and the electronic equipment were hidden behind a curtain. Foraging was evoked by offering food. Techniques and equipment were the same as for the confrontation experiments except that fewer electrode pairs were used, and the sampling rate for digitization reduced to $25 \mathrm{kHz}$. During observations in the large aquar- ium, EODs were recorded on the audio tracks of the videotape.

IDI histograms were calculated using a geometrical progression of bin width with interval duration, as introduced by Graff (1989). The advantage of this procedure is that bin width is proportional to the interval duration represented, avoiding the shortcomings of a constant bin width where resolution is either too crude for short intervals or unreasonably high at large intervals (or both), with IDI ranges as wide as shown by mormyrids. In the present study a bin is characterized by its centre.
Fig. 1. a Superimposed electric organ discharge (EOD) waveforms of ten adult Marcusenius macrolepidotus $(\mathrm{SL}=15.5-22.6 \mathrm{~cm})$, normalized to a positive peak of $1 \mathrm{~V}$, one sample per fish, recorded August 1999, water temperature $25 \pm 0.2^{\circ} \mathrm{C}$, conductivity $100 \pm 10 \mu \mathrm{S} / \mathrm{cm}$. b The same data, 30 times magnified on the $y$-axis to show the weak overshoot following the negative phase. c Two recordings from fish $\mathrm{I}(\mathrm{SL}=$ $21.6 \mathrm{~cm}$ ), made within $30 \mathrm{~min}$; this fish sometimes generated a weak pre-discharge that rarely exceeded one-tenth of the main discharge (as shown in the bottom recording). d Top Recording setup for confrontation tests. Note four pairs of electrodes in two groups that are arranged at right angles, for four separate, simultaneous EOD recordings (only two traces shown at the bottom). In this example the anti-parallel position of the fish allowed assignment of EODs to fish I (black) or fish K (grey) by polarity. Bottom Due to their high amplitude at electrode pair E1, EOD peaks were clipped by the recording equipment

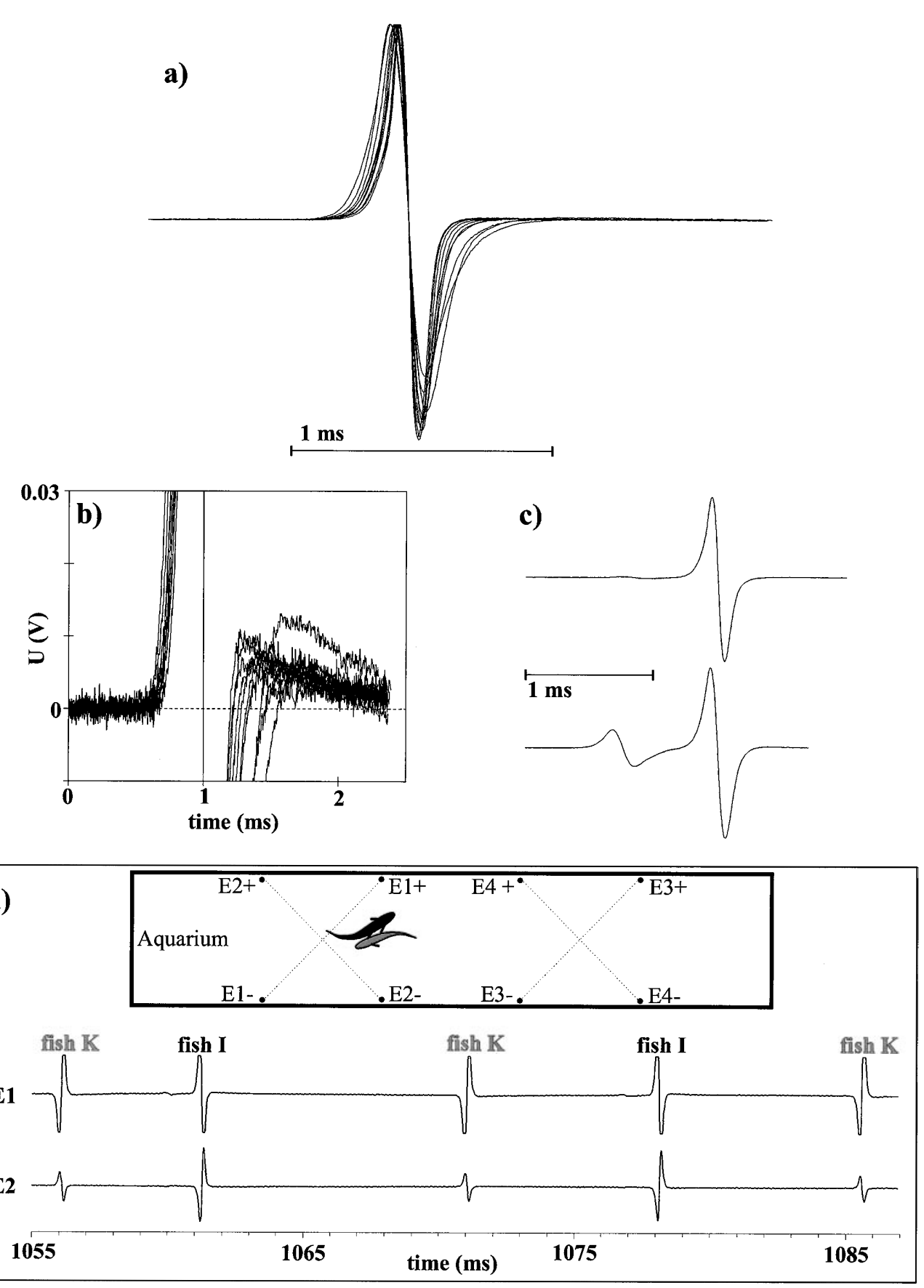




\section{Results}

\section{EOD waveforms}

EOD waveforms of all 11 fish were biphasic with a headpositive phase followed by a negative one (Fig. 1). The positive phase started asymptotically from the baseline; the negative phase was followed by a very weak overshoot, visible only at strong amplification. Fish I sometimes generated an additional weak EOD of variable amplitude that preceded the main EOD by about $0.7 \mathrm{~ms}$ (water tempera- ture $24.9^{\circ} \mathrm{C}$, Fig. 1c). The amplitude of the pre-discharge rarely exceeded one-tenth of the main discharge.

\section{IDI patterns of isolated fish}

During the light phase the fish rested in a porous pot or under a flat stone. Some fish were totally immobile (apart from respiration movements); others were seen hovering within their shelter during the observations. Most of them were also seen lying motionless later on. Some fish changed repeatedly between the two behaviours during the observa-
Fig. 2. Top four diagrams Interdischarge interval (IDI) histograms recorded from four isolated resting fish during the day (fish $\mathrm{G}$ was kept together with fish $C$ in the tank used for confrontation experiments but separated by a solid plastic partition as described in Materials and methods). Data plotted with geometrically increasing bin width (linear axes). IDI $\geq 500 \mathrm{~ms}$ all in last bin. Periods of $5 \mathrm{~s}$ before and after a switch from swimming to resting or vice versa were excluded from analysis. Data for fish B colour-coded for two states of resting, immobile (black) and hovering (grey); also shown as sequential plot of IDI over time (bottom). Water temperature $20 \pm 0.1^{\circ} \mathrm{C}$, conductivity $100 \pm 10 \mu \mathrm{S} / \mathrm{cm}$
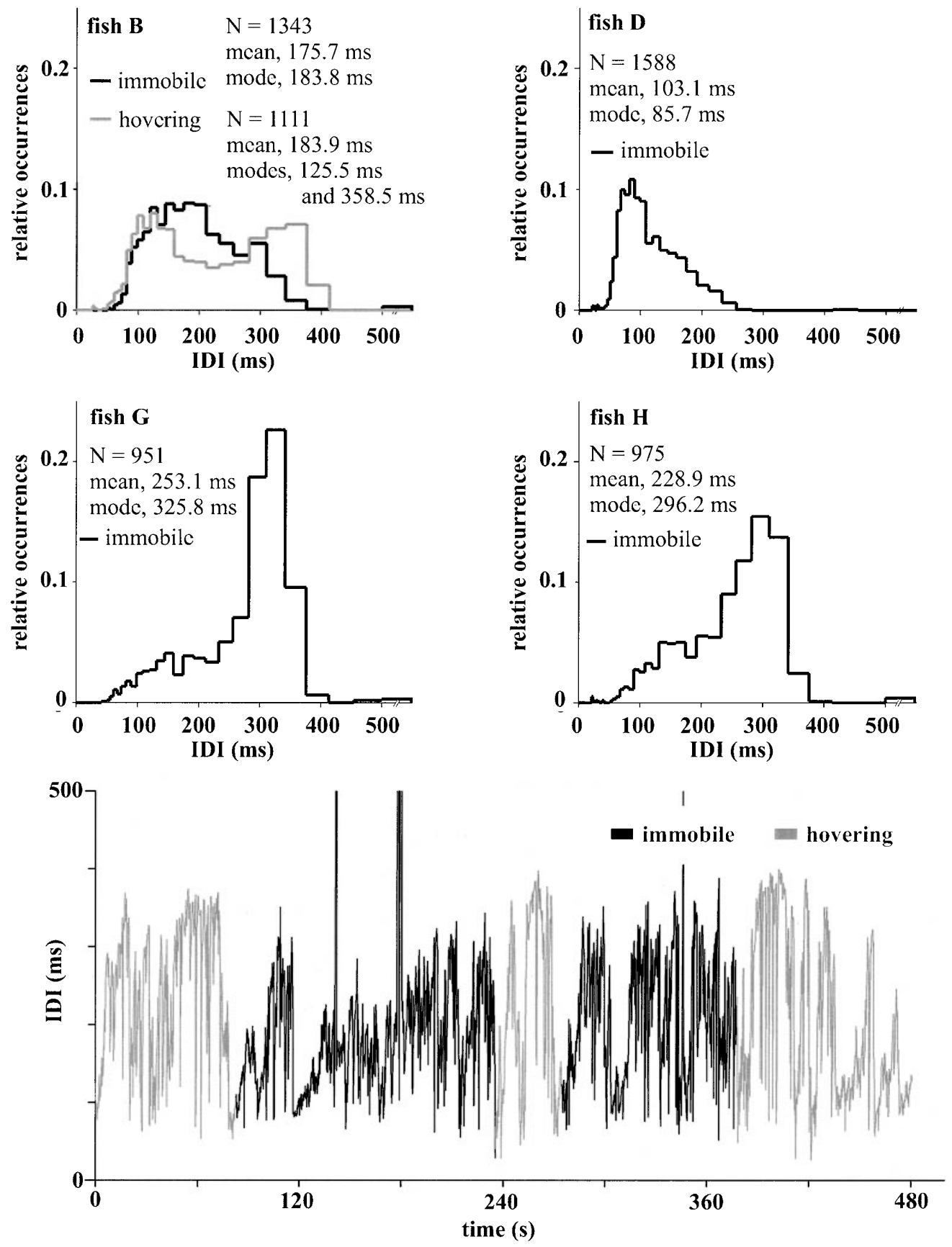
tion period. Figure 2 shows a time plot of an IDI sequence of such an individual and histograms of IDI of resting fish. The IDI modes of the four immobile fish ranged from $85.7 \mathrm{~ms}$ to $325.8 \mathrm{~ms}$, or by a factor of almost 4 . In contrast to fish $\mathrm{B}$ and $\mathrm{D}$, fish $\mathrm{G}$ and $\mathrm{H}$ showed a negatively skewed histogram. Therefore, despite their large modes, IDIs of more than $500 \mathrm{~ms}$ were rare in all four fish. The histograms of fish B became bimodal when the fish hovered (also shown as an IDI sequence at the bottom of Fig. 2). The mean interval duration ranged from about $103 \mathrm{~ms}$ for fish $\mathrm{D}$ to more than $250 \mathrm{~ms}$ for fish G. Very few IDI as short as 18-20 ms were observed in fish $\mathrm{D}$ while hovering between periods of rest- ing motionless: one single or two very short intervals were sometimes interspersed between longer IDIs. A similar pattern was observed in fish E, resting motionless close to fish $\mathrm{A}$ and F. Here IDIs were as short as $16.5 \mathrm{~ms}$ (water temperature $24.7^{\circ} \mathrm{C}$ ).

Foraging fish sometimes moved into a cloud of sinking Chironomus larvae. Usually they searched for food by moving across the bottom with their prominent mental lobe pointing downwards. This behaviour was distinguished from other swimming activities. Compared to resting individuals discharge rate was higher and IDI variation lower. IDI histograms were calculated for three animals searching for
Fig. 3. Top left IDI histograms for three isolated fish when foraging during the day (fish $\mathrm{C}$ was kept together with fish $G$ in the tank used for confrontation experiments but separated by a solid plastic partition as described in

Materials and methods). Top right Sequential plots (IDI over time), sections of the same data. Bottom Extended sequential plot for fish C (for a short period the fish moved out of recording range). Foraging periods are marked by a horizontal bar in all sequential plots. Water temperature $20 \pm 0.1^{\circ} \mathrm{C}$, conductivity $100 \pm 10 \mu \mathrm{S} / \mathrm{cm}$
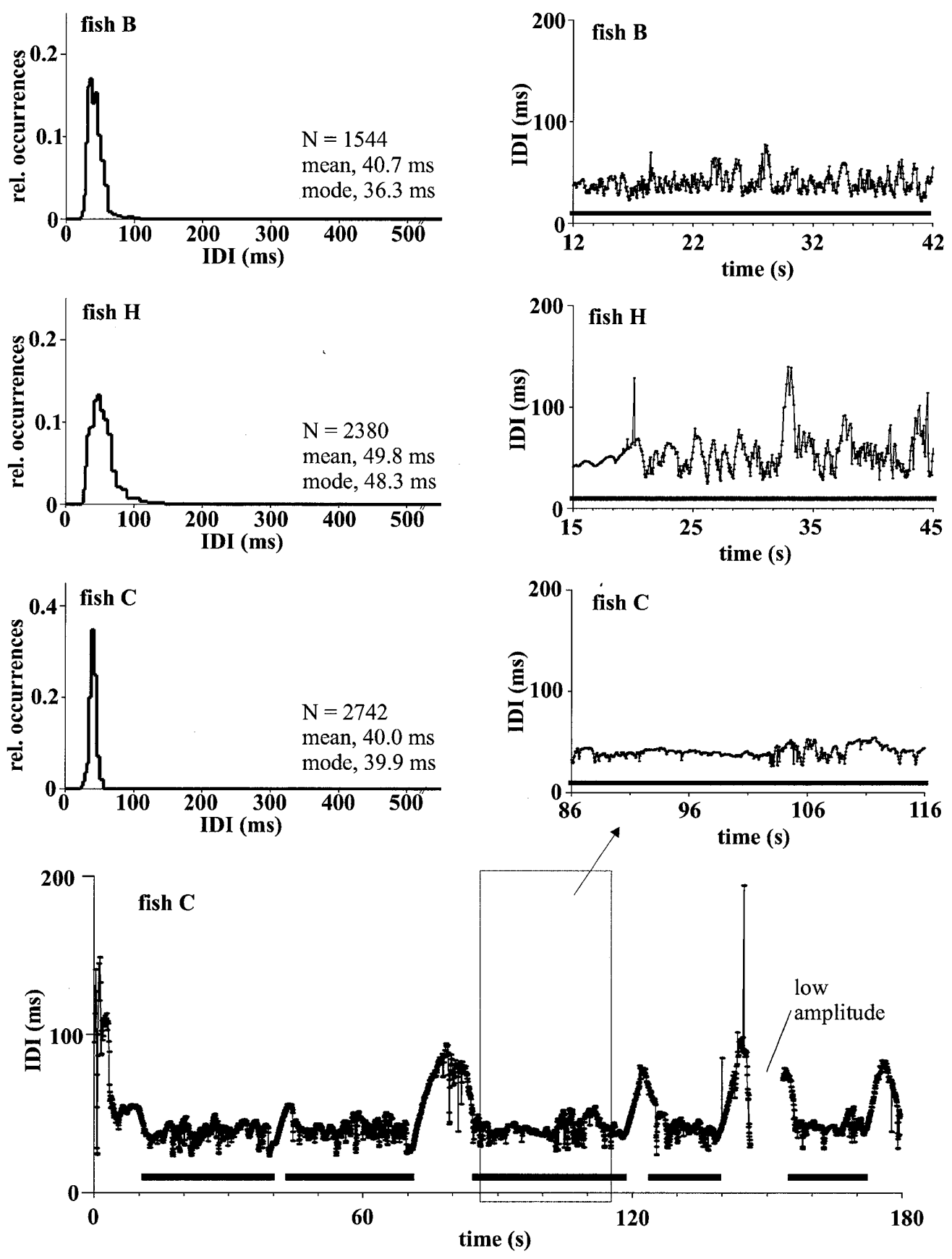
food and feeding (Fig. 3). Almost all IDIs were composed of between 20 and $100 \mathrm{~ms}$. Modes were between 36.3 and $48.3 \mathrm{~ms}$. As shown by sequential plots (Fig. 3), the IDI pattern was temporarily quite constant (fish C), or oscillated around a constant mean (fish $\mathrm{B}$ and $\mathrm{H}$ ). Motor behaviour of fish $\mathrm{C}$ was analysed in detail: the foraging fish moved across the bottom with its prominent mental lobe pointing down- a)
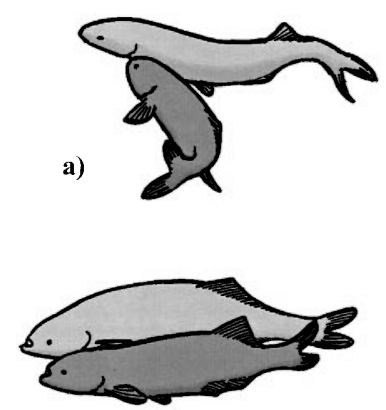

c)
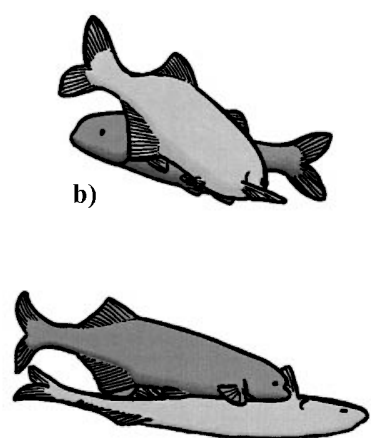

d)
Fig. 4a-d. Examples of agonistic behaviour patterns observed in $M$. macrolepidotus. a Attack, here aimed at the operculum. b Anti-parallel display. c, d Parallel swimming. Fish I sometimes slid sideways under fish $\mathrm{K}$ as is shown in example $\mathbf{d}$ wards, touching the ground, and sometimes fed in this position. Sometimes it briefly lifted its head and changed to a more horizontal position, apparently to chew its prey more thoroughly as suggested by quick head movements. Foraging was interrupted by the fish lifting its head and swimming directly towards its shelter where it hovered for some seconds before it started foraging again. Foraging interruptions were accompanied by an increase in IDI duration (Fig. 3, bottom). One period of foraging in fish $\mathrm{C}$ is presented in detail. Most of the time, interval duration was short and regular. From 103 to $106.4 \mathrm{~s}$ the fish lifted its head from the ground to a horizontal position and the interval pattern became more irregular.

\section{Confrontation tests}

There were five overt behaviour patterns observed during agonistic encounters:

1. Retreating. One fish swimming away from the other, or moving quickly above it in an opposite direction (presumably because an aquarium wall was blocking its way).

2. Parallel swimming. Two fish swimming very closely together in the same direction at slow or medium speed (Fig. 4c, d).
Fig. 5. Interval patterns in two fish that did not fight during a nocturnal encounter. Fish $\mathrm{G}$ (black) became visible on the video images at about $2.5 \mathrm{~s}$ when it started foraging. It continued foraging for the whole sequence shown. Fish C (grey) was probably also foraging when (at $5.8 \mathrm{~s}$ ) it swam towards and above fish $\mathrm{G}$, joining it from behind in foraging (at $11.8 \mathrm{~s}$ ). Water temperature $20.2^{\circ} \mathrm{C}$, conductivity $99 \mu \mathrm{S} / \mathrm{cm}$

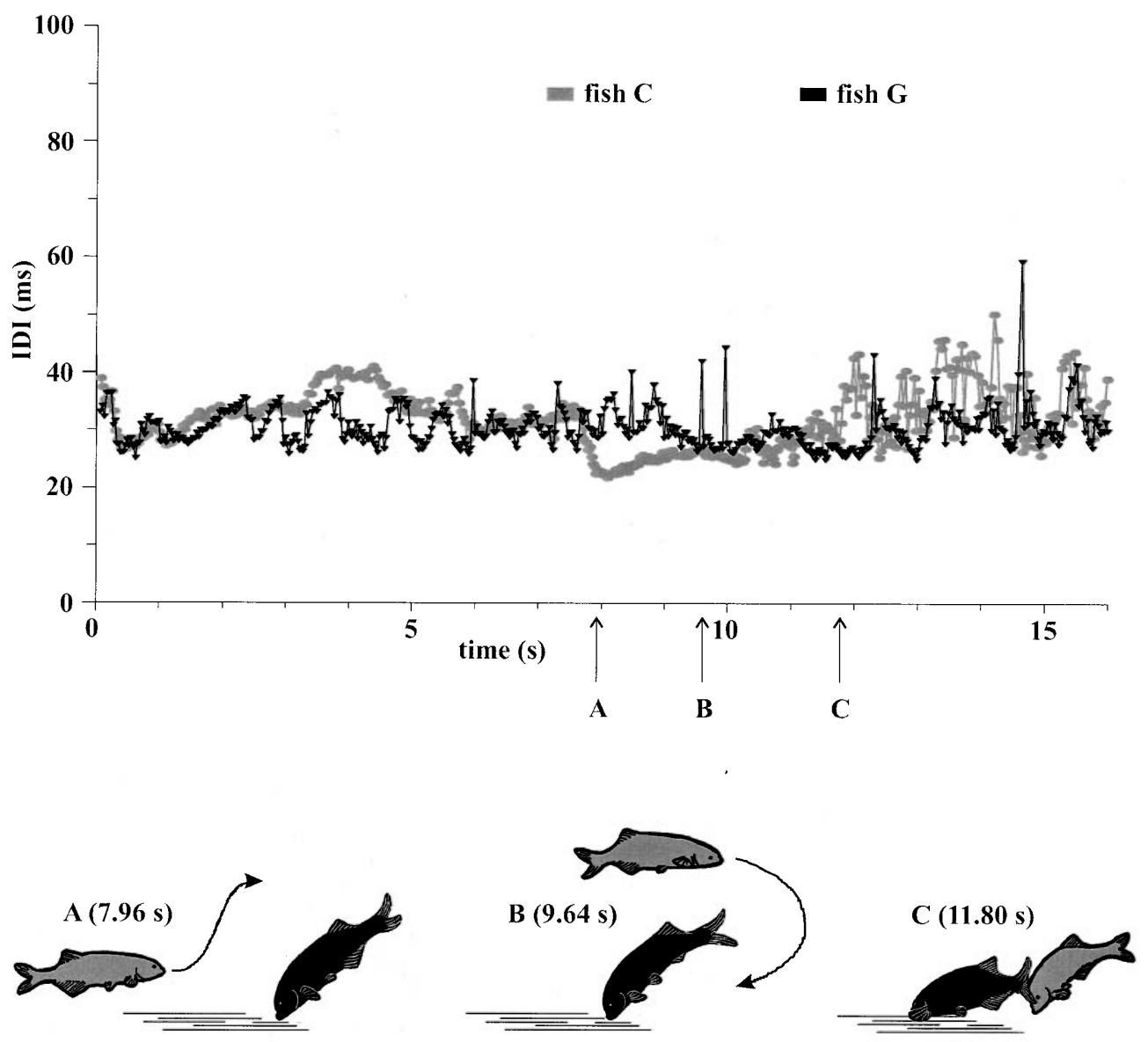


3. Anti-parallel display. Two fish remaining close together and orientated in a head-to-tail position (Fig. 4b). Often they slowly rotated around a common centre.

4. Attack. One fish moving very quickly towards the body of the other and butting it. Preferred points of attack were the area behind the operculum, the middle part of the body, and the caudal peduncle (Fig. 4a).

5. Fleeing/chasing. On losing a fight a fish tried to get away from the winner, which pursued it actively.

True fighting - including attacks, parallel swimming, and anti-parallel displays - was not observed in some encounters. For example, fish $\mathrm{C}$ almost immediately swam towards fish $\mathrm{G}$ when the lights were turned off but did not attack. It swam above and beyond fish G, keeping well clear of it and approaching fish $\mathrm{G}$ from behind (Fig. 5, lower panel). Fish C slightly increased its discharge rate (decrease in IDI duration, Fig. 5, upper panel) when it swam above fish G. The pattern became more irregular when fish $\mathrm{C}$ joined fish $\mathrm{G}$ in foraging. Fish $\mathrm{G}$ did not interrupt foraging in this situation, and its interval pattern hardly changed. Both fish were foraging together for about $30 \mathrm{~s}$. Subsequently (not shown) fish C started to avoid close contact with fish G. It usually retreated to the opposite side of the aquarium that was momentarily not occupied by fish G. Fish G ranged freely within the entire aquarium, foraging most of the time. Both fish actively swam around: Within a period of $26 \mathrm{~min} 33 \mathrm{~s}$, fish $\mathrm{C}$ switched between aquarium sides 116 times, versus 122 times for fish $\mathrm{G}$. Fish $\mathrm{C}$ terminated sharing an aquarium side 96 times by leaving first, versus only 22 such observations for fish G. In most of the latter cases fish G seemed to cross the borderline accidentally when foraging close to it. Only once did fish $G$ interrupt foraging and leave for the opposite side when approached by fish C. Usually fish G did not stop foraging when fish $\mathrm{C}$ swam above and beyond it, but sometimes it chased the fleeing fish $\mathrm{C}$ for a while, especially at a later stage of the encounter. On the other hand, in the middle of the encounter there was a short period (not shown) when fish $\mathrm{C}$ again closed up to fish $\mathrm{G}$ without being chased away immediately.

Quite different from this was the confrontation of fish I with fish K: just before the lights were turned off the solid plastic partition was replaced by a mesh partition. Immediately after dark both fish left their shelter. Figure 6 shows an early sequence when both fish swam around at the mesh partition, passing each other closely. In both fish the EOD rate was rather high and stable throughout (IDI $25-35 \mathrm{~ms}$ ). At closer view (Fig. 6 inset) some fluctuation was apparent and a temporal relationship between both fishes' sequences likely. About $2 \mathrm{~min}$ later this pattern was replaced by a pattern of long, irregular intervals (this change was clearly audible on the headphones) that lasted for about $45 \mathrm{~s}$. The overt behaviour also changed: the fish remained close to the mesh partition and their movements became more coordinated. As suggested by the subsequent behaviour, this change probably occurred within an agonistic context. When the $45 \mathrm{~s}$ were over, high discharge rate (HD, a prolonged series of short IDI) displays were integrated into the discharge pattern. Figure 7a shows a period of $20 \mathrm{~s}$ during which fish performed a mutual anti-parallel display at the mesh partition. Here only fish I generated HDs. IDI duration during the longest HD display was $12-16 \mathrm{~ms}$, with the shortest intervals occurring at the beginning. HDs occurred almost without transition from low-rate inter-HD activity and were later on produced by both fish. The first parallel swimming (not shown) along the mesh partition occurred $20 \mathrm{~s}$ after the anti-parallel display. In Fig. 7b (from about 3 to $5 \mathrm{~s}$ ) both fish tried to break through the mesh partition by forcefully pushing with their heads against it, displaying HDs. At this stage of the encounter the fish also performed
Fig. 6. IDI patterns for fish I and $\mathrm{K}$ at the beginning of a nocturnal encounter when still separated by a plastic mesh partition, before fighting started. At first only fish $\mathrm{K}$ was at the mesh. From 3 to $11 \mathrm{~s}$ both fish swam around at the mesh partition, passing each other closely. Then fish I swam away a little but returned immediately. At $14 \mathrm{~s}$ it left the mesh and returned to its shelter for a short time. Fish K left the partition at $18 \mathrm{~s}$. To allow the direct comparison with time plots of Figs. 7, 8, and 10 a low vertical resolution was chosen. At higher vertical resolution (inset) a temporal relationship between both IDI sequences is seen. Water temperature $20.0^{\circ} \mathrm{C}$, conductivity $97 \mu \mathrm{S} / \mathrm{cm}$

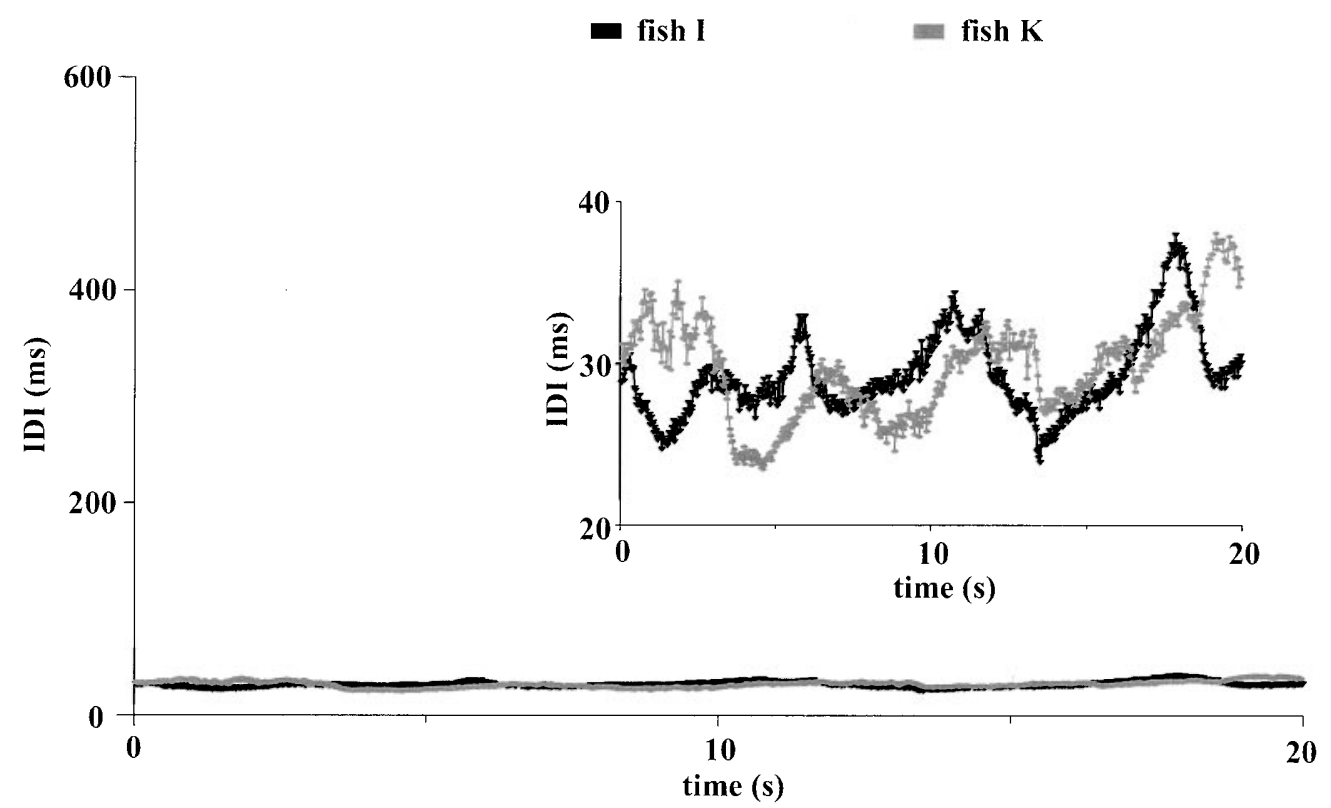


Fig. 7a, b. IDI patterns for fish $\mathrm{I}$ and $\mathrm{K}$ during a nocturnal encounter, when separated by a plastic mesh partition. Fighting had just begun. The fish were closely interacting at the mesh. a From about 2.5 to $3.5 \mathrm{~s}$ the fish were orientated in an almost anti-parallel position (image $A$ ). The subsequent mutual antiparallel display is indicated by a horizontal black bar (only one fish generating high discharge rates (HDs)). The longest HD display is also shown at higher resolution (inset). b Recording starts about $45 \mathrm{~s}$ after that shown in (a) stops. From about 3 to $5 \mathrm{~s}$ both fish tried forcefully to break through the mesh partition (for HD display, see inset). Note the contrast between HD displays and

low inter-HD activity. Water temperature and conductivity as in Fig. 6

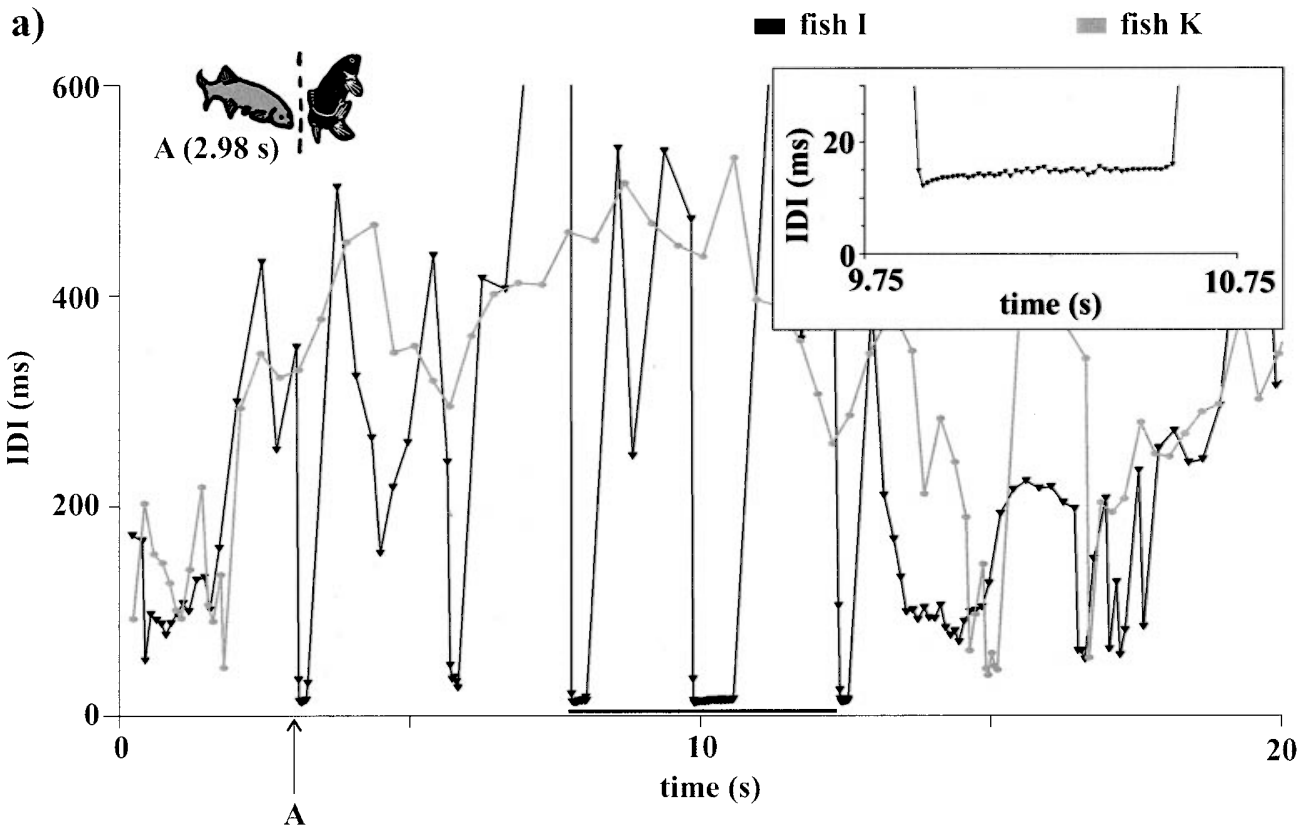

b)

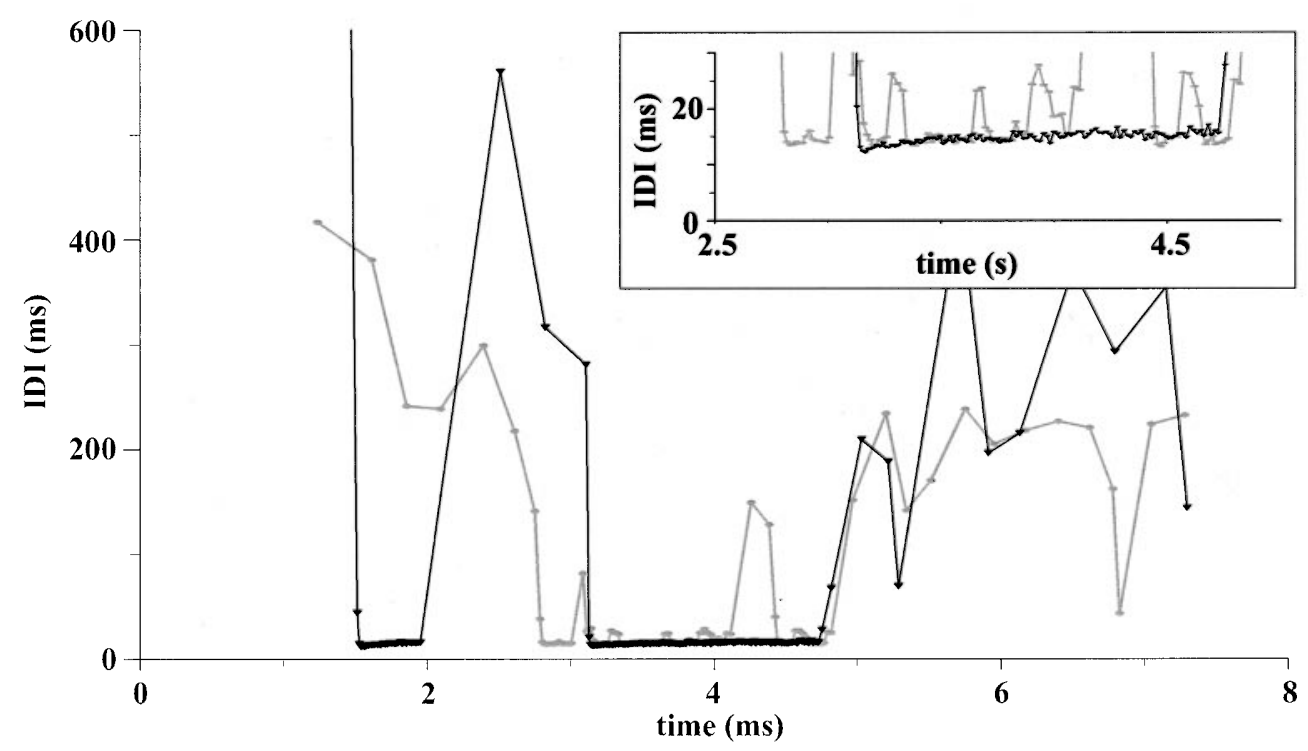

parallel swimming at the mesh partition and tried to attack each other.

On removal of the mesh after $8 \mathrm{~min}$, both fish retreated to their shelters. After about $30 \mathrm{~s}$, fish I swam towards fish K directly. For the next $8 \mathrm{~min}$, parallel swimming, anti-parallel displays, and attacks were observed. Then fish were separated again by the solid plastic partition. Despite a clear difference in body size (Fig. 4d), the smaller fish K showed no escaping behaviour. The video images showed that attacks were forceful but it was not possible to determine whether true bites occurred. Several times during parallel swimming, fish I slid its body sideways under that of fish $\mathrm{K}$ as shown in Fig. 4d. During the fight the whole aquarium was used. Especially during parallel swimming sometimes great dis- tances were covered. Attacks were mainly aimed at the opercular region, the centre of the body, or the caudal peduncle. Figure 8 shows overt behaviour and electrical activity during a prolonged anti-parallel display, terminated by an attack of fish I. Despite the relatively low overt motor activity during the anti-parallel display HDs occurred again.

Overt aggression developed also between fish $\mathrm{C}$ and fish I. When the plastic partition was removed fish I immediately swam towards fish $\mathrm{C}$ and stayed close to it. When the lights were switched off both fish moved within the whole aquarium. No fighting behaviour was observed at this stage of the encounter. At the beginning of the period shown in Fig. 9 fish $\mathrm{C}$ approached fish I and started foraging. The fish passed each other at close distances several times. At the 
Fig. 8. Overt behaviour and electrical activity during an anti-parallel display, performed by fish I (black) and $\mathrm{K}$ (grey) after removal of a separating mesh partition. The period of anti-parallel display is indicated by a horizontal black bar. It was terminated by fish I, attacking fish $\mathrm{K}$ (at $8.92 \mathrm{~s})$. Water temperature and conductivity as in Fig. 6

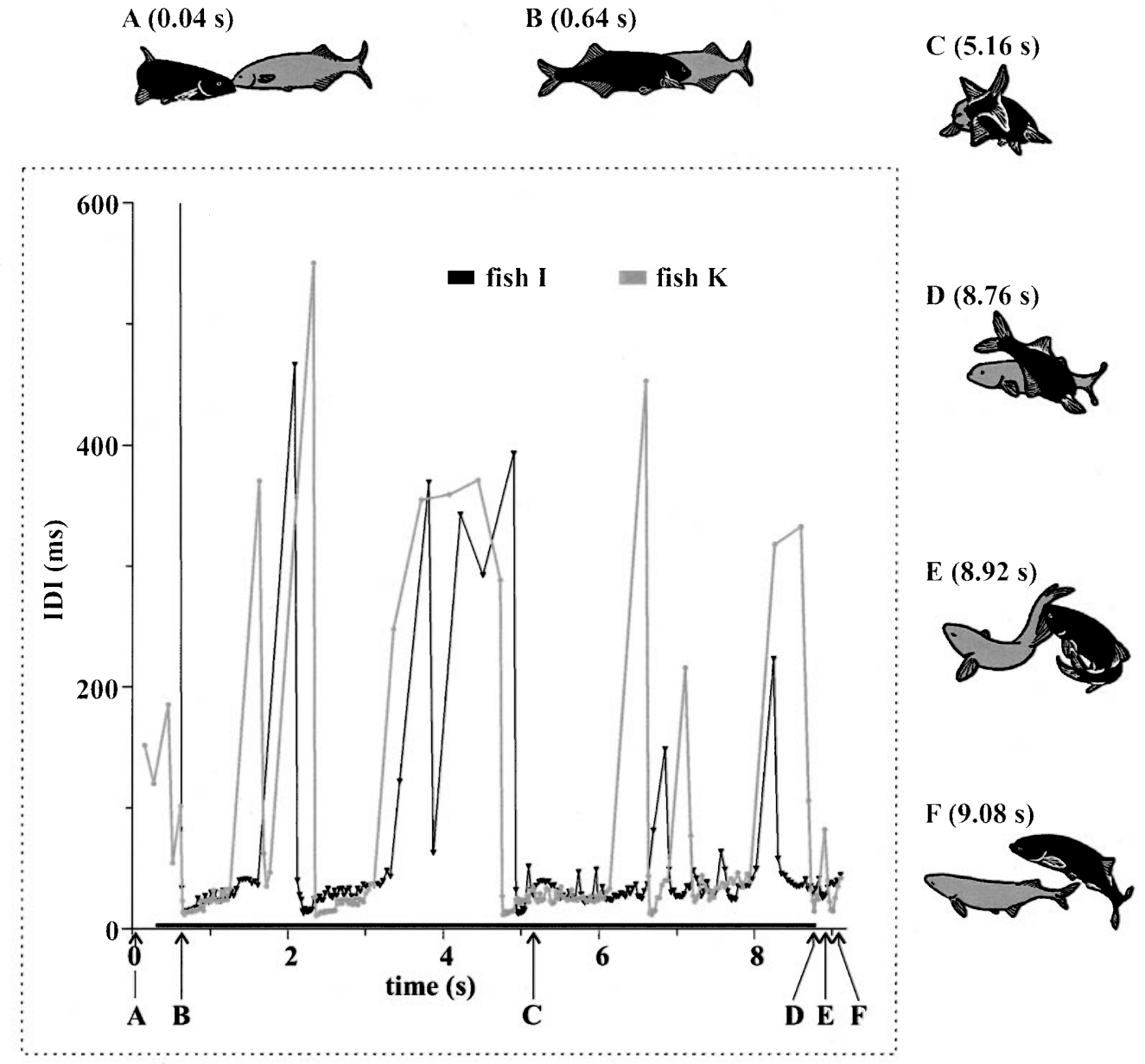

end of the period shown fish I approached Fish C, which stopped foraging and swam away, passing fish I very closely but not attacking. IDIs varied from slightly below $20 \mathrm{~ms}$ to slightly above $100 \mathrm{~ms}$ with fairly smooth transitions as in Figs. 5 and 6 . About $35 \mathrm{~s}$ later fish $\mathrm{C}$ followed fish I to the right end of the tank and true fighting began as indicated by parallel swimming. Figure 10 shows a sequence of fish I attacking fish C. About $0.6 \mathrm{~s}$ later both fish turned around and fish I maintained its position close to fish $\mathrm{C}$ as if performing an anti-parallel display. However, fish $\mathrm{C}$ did not reciprocate the display but turned slowly around and finally attacked fish I. Both attacks were accompanied by a sharp increase of discharge rate. During the subsequent period of parallel swimming EODs could no longer be assigned to individuals. The fight ended after about $90 \mathrm{~s}$ when fish $\mathrm{C}$ was clearly fleeing, being chased by fish I. Though not investigated in detail, from monitoring the discharges on the headphones it seemed likely that later on one fish stopped discharging.

Examples of IDI patterns observed during anti-parallel displays of fish I, K, and C are shown in Fig. 11. All patterns included HDs but differences in time course were apparent both between and within individuals. However, IDI histograms during mutual anti-parallel displays were very similar for all three fish (Fig. 12a). All histograms showed a distinct mode at $15.4 \mathrm{~ms}$ and another mode at $24.8 \mathrm{~ms}$ (fish $\mathrm{C}$ : $27.3 \mathrm{~ms}$ ). Fish $\mathrm{K}$ and $\mathrm{C}$ showed a weak third mode at $33.0 \mathrm{~ms}$ and $38.1 \mathrm{~ms}$, respectively. The data for all three fish were combined and compared with the combined data for the three isolated foraging fish, already presented in Fig. 3, and with IDI patterns recorded either from fish that did not fight at all (Fig. 5) or from before fighting had started (Figs. 6, 9). Both modes (15.4 ms, and $24.8 \mathrm{~ms}$ ) were below the single histogram modes observed in foraging fish $(39.9 \mathrm{~ms})$, or in fish during non-agonistic interactions $(30.0 \mathrm{~ms})$. Intervals as short as $15.4 \mathrm{~ms}$ were observed neither in isolated fish when foraging nor in pairs of fish during non-agonistic interactions. Furthermore, the IDI sequences were different: IDI patterns observed during fights (Figs. 7, 8, 10,11) were characterized by abrupt changes between HD displays and lowrate inter-HD activity. Such abrupt changes were not found during non-agonistic interactions (Figs. 5, 6, 9) nor in isolated foraging fish (Fig. 3).

Agonistic behaviour patterns like anti-parallel display and attack were also observed in young fish (reared in an aquarium), for example, at SLs of about $30 \mathrm{~mm}$ and $45 \mathrm{~mm}$. Though not investigated in detail aggression was also observed in female fish: among three females (fish B, D, and 

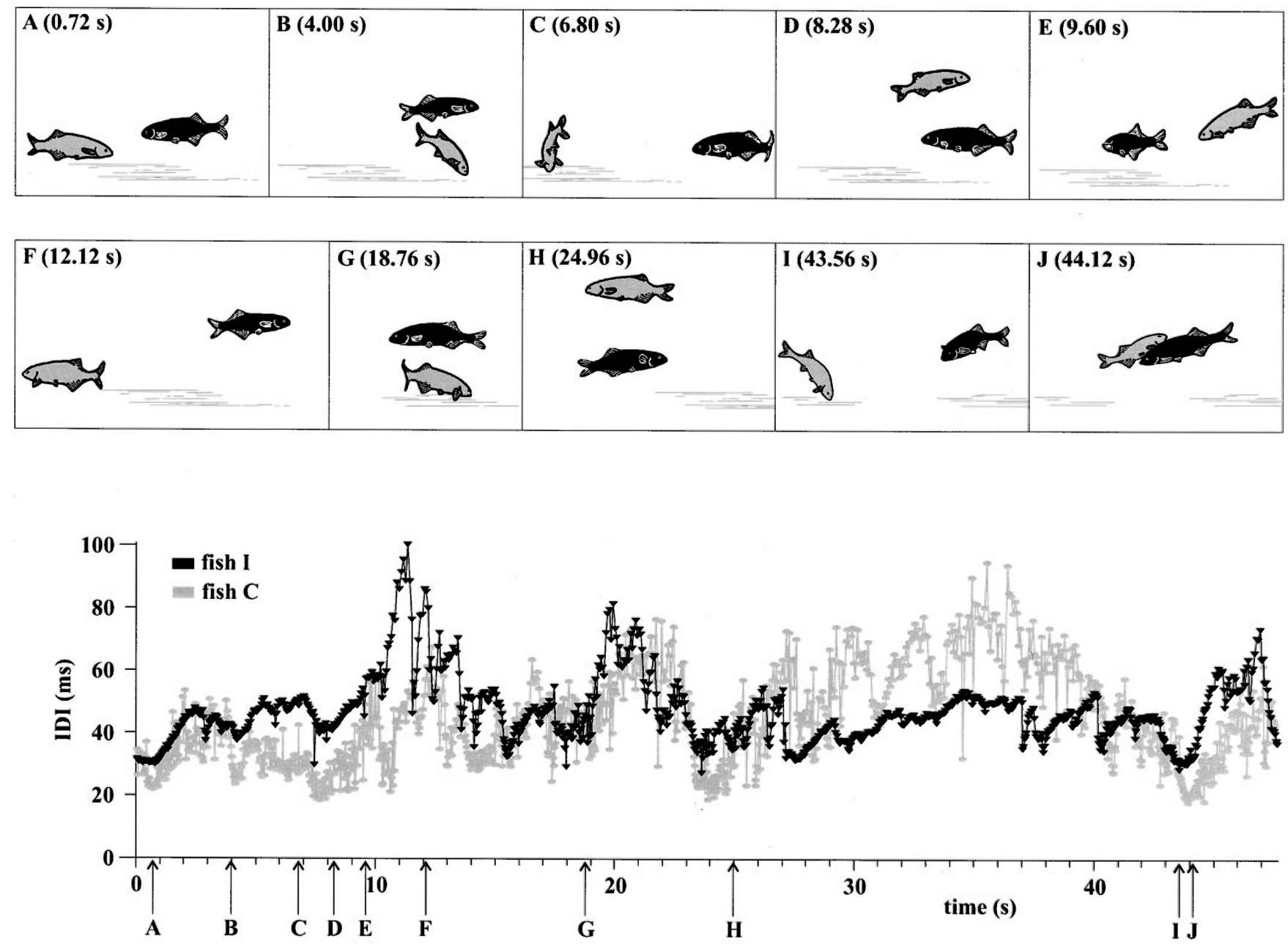

Fig. 9. Overt behaviour and electrical activity during a nocturnal encounter before fighting started. Fish C (grey) approached (image $A$ ) fish I (black) and started foraging $(B, C)$. It then turned around and approached fish I from behind $(D, E)$ and swam to the centre of the aquarium $(F)$. Fish I followed fish $\mathrm{C}$ some seconds later and passed it $(G)$. Fish $\mathrm{C}$ swam to the right part of the aquarium, turned around, swam above and beyond the approaching fish I to the left $(H)$ and went

out of sight for some seconds while fish I stayed at the right end of the aquarium close to the empty shelter (not shown) of fish C. Fish I then also swam to the left and approached the foraging fish $C(I)$, which swam away, passing fish I very closely $(J)$. Note that despite several critical situations like close passings, no overt aggression and no HD displays were observed. The fish started fighting about $35 \mathrm{~s}$ later. Water temperature $19.9^{\circ} \mathrm{C}$, conductivity $99 \mu \mathrm{S} / \mathrm{cm}$

$\mathrm{H})$ in an aquarium $2.4 \times 0.5 \times 0.6 \mathrm{~m}$ high, fish $\mathrm{D}$ was intensely chased by fish $\mathrm{H}$ and severely wounded. Plastic partitions were necessary to separate the individuals.

Figure 13 shows daylight recordings from three fish, A, $\mathrm{E}$, and $\mathrm{F}$, that were resting motionless within less than $0.5 \mathrm{~m}$ distance from each other in the big aquarium. Most IDIs were between about 50 and $120 \mathrm{~ms}$; IDIs longer than $150 \mathrm{~ms}$ were mostly shown by fish F. A fourth fish, fish L, entered the scene several times, unobserved on the video but clearly demonstrated by its EODs that were recorded along with those of the other fish for short periods of time, at very weak amplitude but relatively high discharge rate. Just when the EODs of fish $\mathrm{L}$ became detectable by the recording equipment, the other fish stopped discharging almost simultaneously. After a moment the EODs of fish L were no longer detectable, and the other fish resumed discharging one after the other. Eleven discharge arrests for all three fish were observed within a period of $15 \mathrm{~min}$, in 8 of which the dis- charges of the fourth fish became audible on the headphones. Three sequences were studied in full detail and the three individuals always showed the same sequence of resuming discharging. Fish $L$ that evoked social silence in the three other fish was often seen chasing another fish, but it was never seen being chased itself.

\section{Discussion}

EOD waveform

A clear sexual dimorphism of EOD waveform was found by Kramer (1997a, b) in M. macrolepidotus from the Upper Zambezi (Namibia). The EODs of sexually mature males were of considerably longer duration (several milliseconds) than those of females and juveniles (half a millisecond). 
Fig. 10. Overt behaviour and IDI patterns recorded from fish I (black) and C (grey) during a nocturnal agonistic encounter. Fish I attacked fish $\mathrm{C}$ at $0.7 \mathrm{~s}$ (image $B$ ). From about $4 \mathrm{~s}$ on fish I maintained its position as if performing an anti-parallel display $(F, G)$. However, fish C did not join in this display but slowly turned around and finally attacked fish I at $5.7 \mathrm{~s}(G, H)$ During the subsequent period of parallel swimming $(I)$ EODs could no longer be assigned to specific individuals. Water temperature and conductivity as in Fig. 9
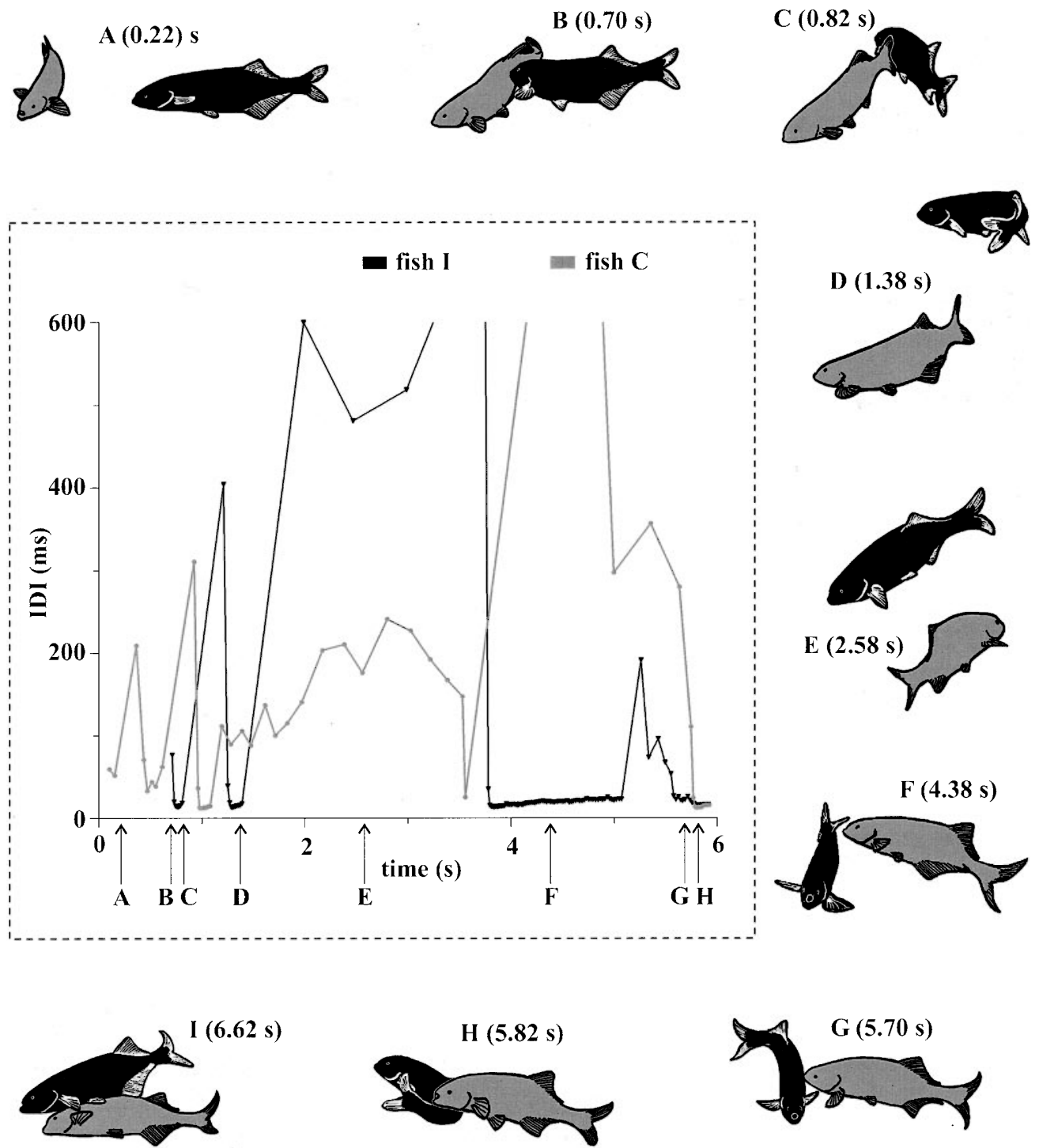

Though some variability in EOD duration between individuals can be seen in Fig. 1, there is no sexual dimorphism. The lack of a sexual dimorphism in EOD waveform in bulldogs from South Africa has already been observed in a field study that considers M. macrolepidotus from South Africa a distinct species (Kramer et al. 1998, and in preparation).

\section{Diurnal overt behaviour and electrical activity}

Several species of mormyrids show a variety of motor activities even during the day. Some stay almost immobile in a dark place whereas others tend to be restless (review, Kramer 1990). Prolonged hovering seemed to result from disturbances by the researcher. Nevertheless, disturbances by other animals (e.g., elephants, hippopotami, cattle, or even humans) may be part of the natural situation. Other factors that influence behaviour during the day could be the presence of conspecifics and their density, and the quality of the available hiding places. Dense vegetation, as offered in the large aquarium, supports resting motionless, whereas a fish in a rock hole or a porous pot can lie motionless or hover. In their natural habitat, this species was found hiding during the day below undercut riverbanks, especially where there was a smooth countercurrent and dense beard-like roots from trees hanging into the water (B. Kramer, personal observation).

Compared to other mormyrids (review, Kramer 1990), a high inter-individual variability of resting IDI histograms has been found by Graff (1986, cited in Kramer 1990) in $M$. macrolepidotus imported from Tanzania. In contrast to the considerable individual variability in isolated resting fish, IDI modes for the three isolated foraging fish studied were similar to each other. The oscillating patterns (Fig. 3) are quite different from daytime observations in foraging $M$. senegalensis (Scheffel and Kramer 1997). The differences in IDI patterns among foraging fish could be due to differences in food density, or they could reflect changes between 
Fig. 11. Examples of IDI patterns observed during mutual anti-parallel displays at night ( $\mathbf{c}$ is part of the sequence already shown in Fig. 8 at lower vertical resolution). Periods of HD are present in all diagrams. However, some variability in time patterns is evident (a-d). Water temperature and conductivity as in Fig. 6 and 9
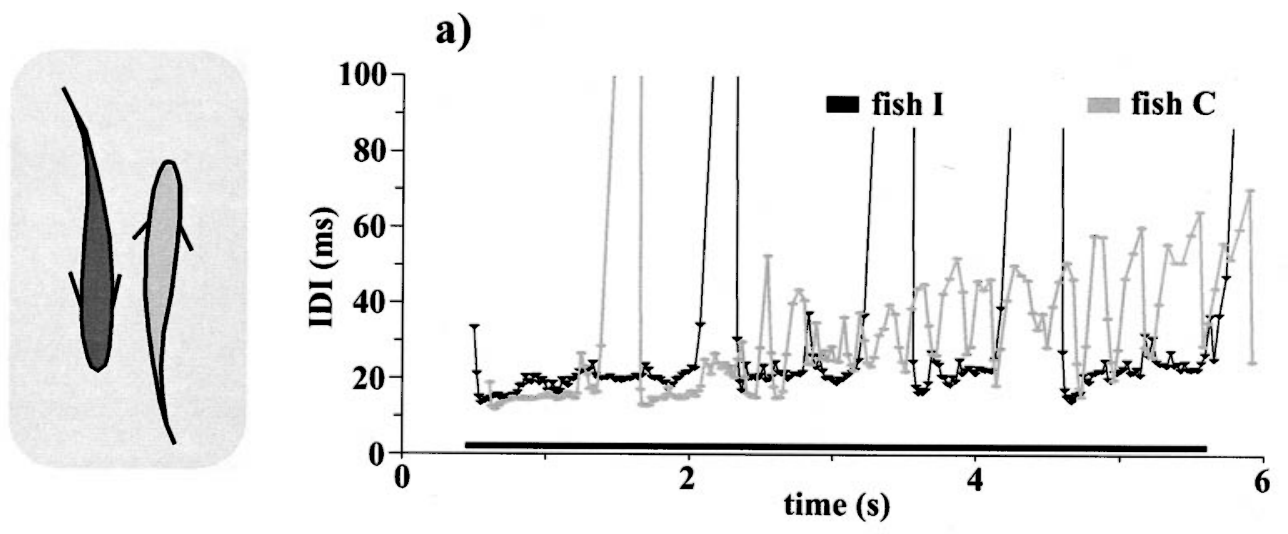

b)

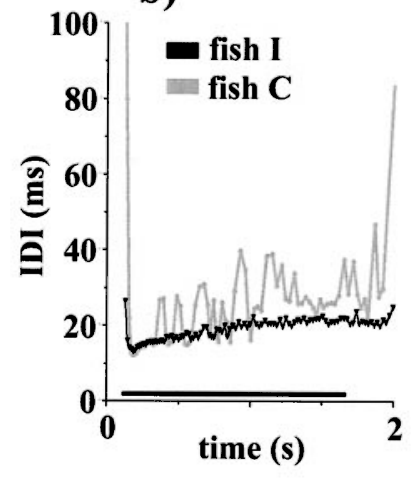

c)

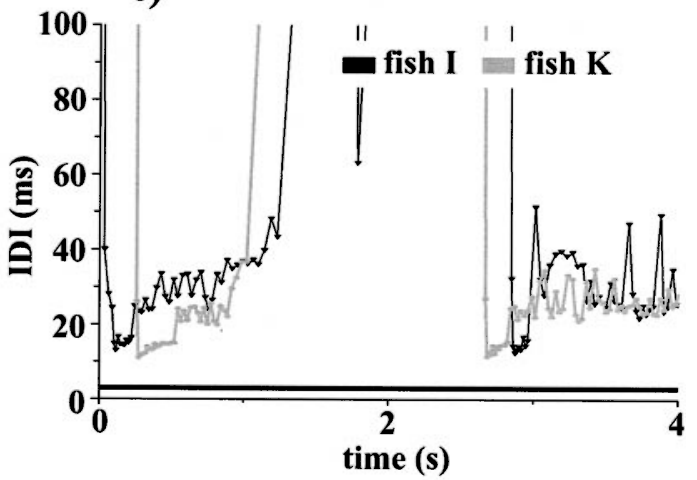

d)

a fish I fish K

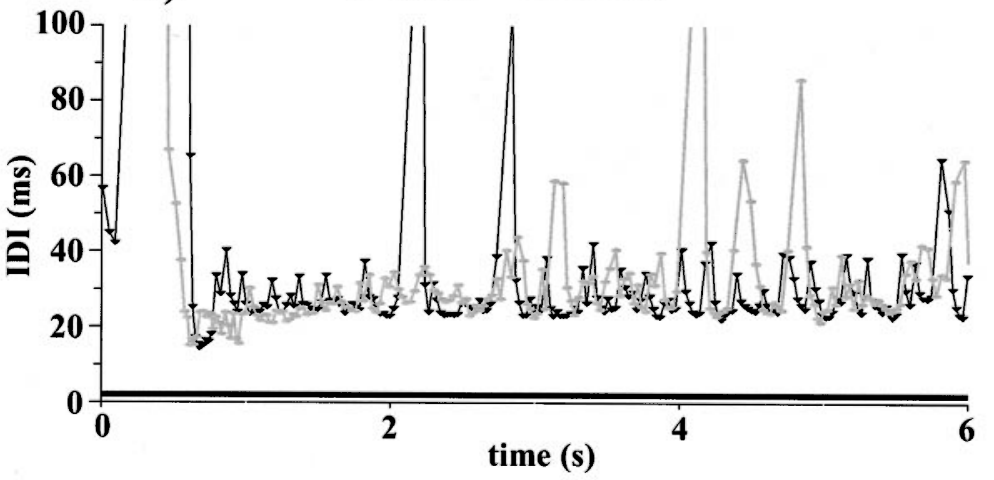

motor activities (searching or uptake of food) as described for fish $\mathrm{C}$. Since the fish were isolated no communication function was involved. Each individual could have chosen its own momentarily preferred discharge rhythm, also using non-electrical sensory modalities (von der Emde and Bleckmann 1998). From our observations it is not clear whether the foraging fish used active electrolocation for prey detection.

Overt behaviour during agonistic interactions

Anti-parallel display and attacks have been observed in other mormyrids as well, for example, in Gnathonemus petersii (Bauer 1972; Bell et al. 1974; Kramer and Bauer
1976; Serrier and Moller 1981) and Pollimyrus isidori (Bratton and Kramer 1989). Parallel swimming has not been reported yet in mormyrids except for a brief note by Serrier and Moller (1981: "too infrequent as to be subject to statistical comparisons"). Parallel swimming was not observed in the closely related M. senegalensis (Scheffel and Kramer 1997), but they did show mouth fighting not observed in the present study.

Fish $\mathrm{C}$ approached fish $\mathrm{G}$ from behind (Fig. 5), thus minimizing the danger of being surprised by an attack itself. Fish $\mathrm{G}$ not only tolerated this but even continued feeding with little change in its electrical activity. In an agonistic encounter the orientation of fish $\mathrm{G}$ would allow immediate fleeing but was extremely unsuited for fighting. Therefore, probably neither fish intended to fight. HD displays, as they 
Fig. 12. a Histograms of IDI recorded during anti-parallel displays in fish $\mathrm{I}, \mathrm{K}$, and $\mathrm{C}$, including data from Figs. 7a, 8 , and 11. b Histogram of the combined data for these three fish shown together with a histogram of the combined data for three isolated foraging fish (individually shown in Fig. 3) and the combined data for nonagonistic interactions, recorded either in an encounter where no fighting occurred, or prior to the fights (data individually shown as time plots of IDI in Figs. 5, 6, and 9 ). IDI $\geq 98.75 \mathrm{~ms}$ all in last bin. Water temperature $20 \pm 0.2^{\circ} \mathrm{C}$, conductivity $100 \pm 10 \mu \mathrm{S} / \mathrm{cm}$
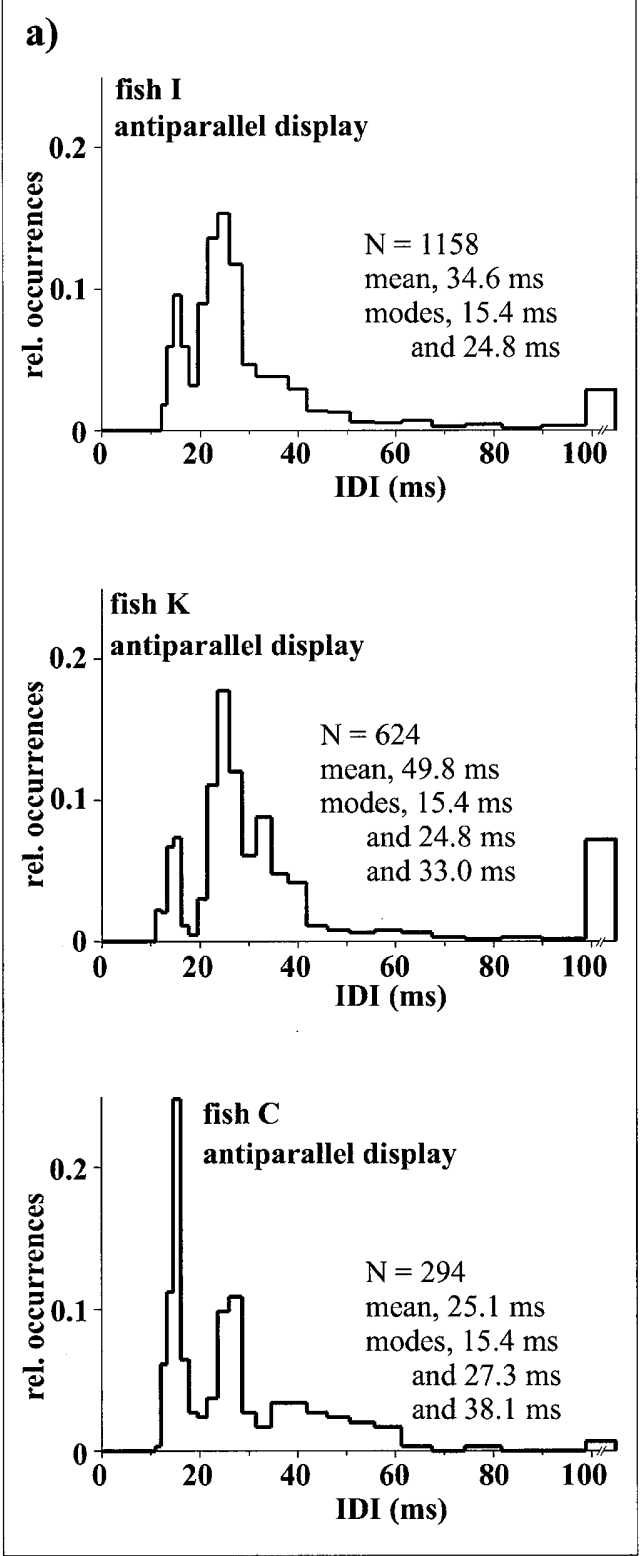

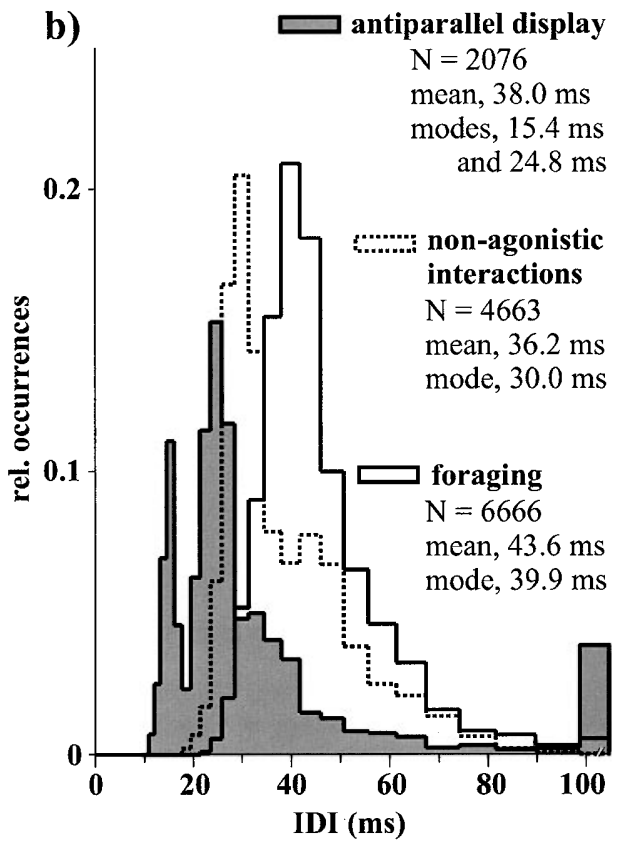

were observed in fighting pairs of fish (fish I and K, fish I and $\mathrm{C}$ ), did not occur in the entire encounter (as revealed by monitoring the discharge rate on the headphones). It seems likely that fish $\mathrm{G}$ had already become the dominant fish and fish $\mathrm{C}$ submissive before the observation started.

Electrical activity during agonistic interactions

All previous studies of agonistic behaviour in mormyrids (review, Kramer 1990; Scheffel and Kramer 1997, 2000) have pointed out the occurrence of HDs (prolonged series of short IDIs) that were found rarely within any other context. The present study confirms the close association of HD with agonistic behaviour. We focussed on the anti-parallel display, since it was best suited for our method of discrimi- nating between EODs from different individuals of the same species. However, examples of other agonistic behaviours that were accompanied by HDs were also observed.

As the histograms (Fig. 12) show, the HDs were composed of two kinds of IDI, around 15.4 and $24.8 \mathrm{~ms}$ at a water temperature of $20^{\circ} \mathrm{C}$. A similar bimodal frequency distribution of IDI was found in G. petersii, attacking Mormyrus rume (Kramer 1974; Kramer and Bauer 1976). The aggressive signal character of HD displays was demonstrated by playback experiments in G. petersii (Kramer 1979).

During the confrontation test of fish $\mathrm{I}$ and $\mathrm{K}$ there seemed to be a period of initial approaching and probing characterized by a rather high and stable EOD rate observed in both fish. The HD displays, as subsequently shown by fish I, could function as a threat signal. In the dark 
Fig. 13. IDI patterns recorded from a group of three individuals, resting together in a large aquarium during the day. When the EODs of a fourth individual ( fish $L$ ) became detectable the others temporarily stopped their electrical activity. Water temperature $24.7^{\circ} \mathrm{C}$, conductivity $106 \mu \mathrm{S} / \mathrm{cm}$

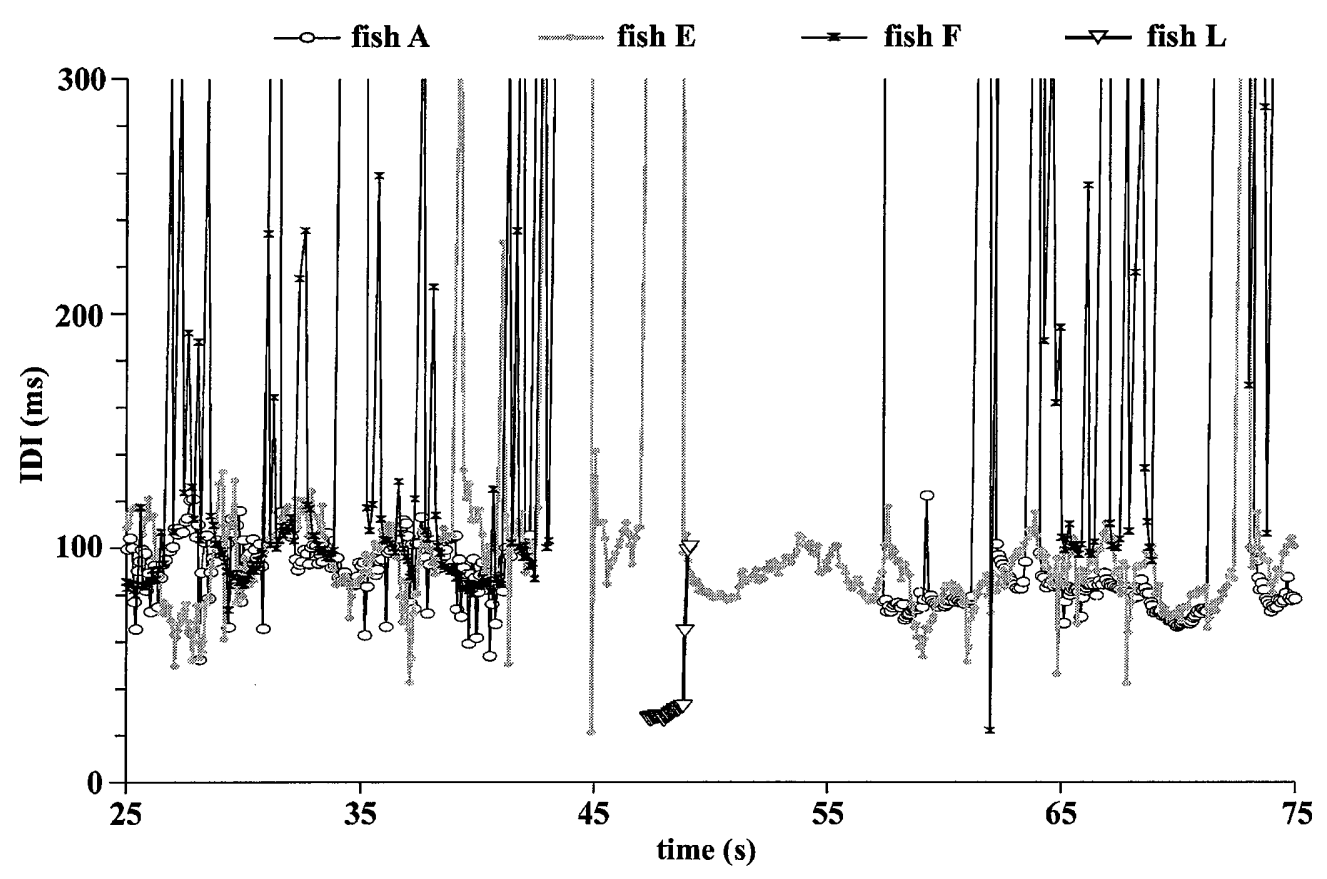

when visual communication is limited, the presentation of a long-duration HD could signal power and strength, similar to raising unpaired fins in cichlids, which makes the fish appear bigger (Baerends and Baerends-van Roon 1950), or the roaring in deer stags (Clutton-Brock and Albon 1979). It is unknown whether the ability to give prolonged HD displays is directly correlated with physical strength in $M$. macrolepidotus. By changing abruptly from low-rate interburst activity to burst activity and vice versa, a strong contrast is created, possibly an analogy to visual contrasts like warning colours of dangerous insects (e.g., Vespula).

According to classical ethological theory, threat behaviour signals a high level of both attack and flee tendencies. By ritualization, a threat discharge pattern could have evolved from regularly alternating "attack" and "escape" discharge sequences. But the changes between HDs and low inter-HD activity observed in the present study during a prolonged agonistic encounter are not nearly as regular as those recorded from M. senegalensis (Scheffel and Kramer 1997).

The confrontation tests as well as the observations in the large aquarium during daylight showed that social encounters between adult male bulldogs do not always lead to fighting. One possible reason for fighting may be the establishment of a dominance hierarchy for territory ownership. This is suggested by the example of fish L, which successfully claimed almost all of the large aquarium for itself while fish $\mathrm{A}, \mathrm{E}$, and $\mathrm{F}$ were reduced to one corner during the day. As the frequent changes between compartments of fish $\mathrm{C}$ and $\mathrm{G}$ indicated, their aquarium probably was too small to allow the subdominant fish to defend a territory of its own.

Discharge arrest over a prolonged period of time was found to be part of the behaviour of defeated individuals (Kramer 1976; Bratton and Kramer 1989). Cessation of electrical activity can also occur without overt fighting. Moller et al. (1989) concluded that prolonged discharge pauses observed in caged Brienomyrus niger, termed "social silence", were communication displays. Similar discharge pauses have been observed in freely ranging Petrocephalus catostoma when trespassing on a neighbour's territory (Scheffel and Kramer 2000), or under experimental condition among a group of Marcusenius macrolepidotus (Graff 1986, cited in Moller 1995, p. 255).

In freely swimming fish often moving at great speed the discrimination between conspecific (i.e., very similar) EODs remains a difficult job. HD displays were observed during several high-intensity agonistic interactions, often during periods of relatively low overt motor activity (antiparallel display). An increased need for active electrolocation information during close interaction would be only an incomplete explanation, since HD displays characteristically alternated with periods of very low discharge rate. Therefore it seems reasonable to assume a communication function for the HD display. The signal character of the HD display has been experimentally proven for only one (Kramer 1979) of the approximately 200 mormyrid species.

Acknowledgements We wish to thank Dr. F.H. van der Bank (Rand Afrikaans University, South Africa) and Dr. J. Engelbrecht (Mpumalanga Parks Board, South Africa) for sampling and exporting our test fish from the field. The observations and experiments comply with the current laws of Germany. This work was supported by the Deutsche Forschungsgemeinschaft (DFG), grants $\mathrm{Kr} 446 / 10-4$ and $\mathrm{Kr} 446 / 10-5$.

\section{References}

Baerends GP, Baerends-van Roon JM (1950) An introduction to the study of the ethology of cichlid fishes. Behaviour [Suppl] 1:1-242

Bauer R (1972) High electrical discharge frequency during aggressive behaviour in a mormyrid fish, Gnathonemus petersii. Experientia 28:669-670 
Bell CC, Myers JP, Russell CJ (1974) Electric organ discharge patterns during dominance related behavioral displays in Gnathonemus petersii (Mormyridae). J Comp Physiol 92:201-228

Bratton BO, Kramer B (1989) Patterns of the electric organ discharge during courtship and spawning in the mormyrid fish, Pollimyrus isidori. Behav Ecol Sociobiol 24:349-368

Clutton-Brock TH, Albon SD (1979) The roaring of red deer and the evolution of honest advertisement. Behaviour 69:145-170

Graff B (1987) Recording electrophysiological signals from small moving animals: electrode fixation and low torque swivel for recording a weakly electric fish in a group. J Neurosci Methods 19:95-104

Graff B (1989) Firing activity of the weakly electric fish Marcusenius macrolepidotus (Mormyridae, Teleostei): logarithmic repartition of inter-pulse intervals and sequential inequality testing. Behaviour 109:258-284

Kramer B (1974) Electric organ discharge interaction during interspecific agonistic behaviour in freely swimming mormyrid fish. A method to evaluate two (or more) simultaneous time series of events with a digital analyser. J Comp Physiol 93:203-235

Kramer B (1976) Flight-associated discharge pattern in a weakly electric fish, Gnathonemus petersii (Mormyridae, Teleostei). Behaviour 59:88-95

Kramer B (1979) Electric and motor responses of the weakly electric fish, Gnathonemus petersii (Mormyridae), to play-back of social signals. Behav Ecol Sociobiol 6:67-69

Kramer B (1990) Electrocommunication in teleost fishes: behavior and experiments. Springer, Berlin Heidelberg New York

Kramer B (1996) Electroreception and communication in fishes. Fischer, Stuttgart

Kramer B (1997a) Electric organ discharges and their relation to sex in mormyrid fishes. Naturwissenschaften 84:119-121

Kramer B (1997b) A field study of African elephantfish (Mormyridae, Teleostei): electric organ discharges in Marcusenius macrolepidotus (Peters, 1852) and Petrocephalus catostoma (Günther, 1866) as related to sex. J Afr Zool 111:313-341
Kramer B, Bauer R (1976) Agonistic behaviour and electric signalling in a mormyrid fish, Gnathonemus petersii. Behav Ecol Sociobiol $1: 45-61$

Kramer B, Kuhn B (1993) Electric signaling and impedance matching in a variable environment. Naturwissenschaften 80:43-46

Kramer B, Westby GWM (1985) No sex difference in the waveform of the pulse type electric fish, Gnathonemus petersii (Mormyridae). Experientia 41:1530-1531

Kramer B, Van der Bank FH, Skelton PH (1998) Two new species of snoutfish (Mormyridae) from South Africa: evidence from electric organ discharges. In: African fishes and fisheries: diversity and utilisation (abstracts). Paradi Conference, Grahamstown, South Africa, p 50

Moller P (1995) Electric fishes. History and behavior. Chapman and Hall, London

Moller P, Serrier J, Bowling D (1989) Electric organ displays during social encounter in the weakly electric fish Brienomyrus niger L. (Mormyridae). Ethology 82:177-191

Scheffel A, Kramer B (1997) Electrocommunication and social behaviour in Marcusenius senegalensis (Mormyridae, Teleostei). Ethology 103:404-420

Scheffel A, Kramer B (2000) Electric signals in the social behavior of sympatric elephantfish (Mormyridae, Teleostei) from the Upper Zambezi River. Naturwissenschaften 87:142-147

Serrier S, Moller P (1981) Social behaviour in a mormyrid fish (Mormyriformes, Pisces): short and long term changes, associated with repeated interactions. In: Szabo T, Czeh G (eds) Advances in physiological sciences, vol 31. Sensory physiology of aquatic lower vertebrates. Pergamon Press/Akadémiai Kiadó, Budapest, pp 221233

Skelton P (1993) A complete guide to the freshwater fishes of southern Africa. Southern, Halfway House, South Africa

Von der Emde G, Bleckmann H (1998) Finding food: senses involved in foraging for insect larvae in the electric fish Gnathonemus petersii. J Exp Biol 201:969-980 